\title{
Study warns of 'avoidable' risks of CT scans
}

\section{Jim Giles, London}

Hundreds of fatal cases of cancer are being induced in children every year by hospital scans that could be replaced by other diagnostic methods, researchers have claimed.

The researchers' concern centres on the use of computed tomography (CT) scans; these create images of internal organs by combining X-rays taken from different angles. An initial analysis by David Brenner, a radiation biologist at Columbia University in New York, suggests that a single year of paediatric CT scans will ultimately cause 2,500 cancer deaths in the United States alone. But a survey of radiologists suggested that a third of these scans could be avoided, adds Brenner, who presented his work at an international conference in London "Children with Leukaemia: Incidence, Causal Mechanisms and Prevention" — on 7 September.

The use of childhood CT scans has mushroomed since 1990, when a new generation of devices cut the scanning time from 1 minute to 1 second. The shorter scans have been a boon to clinicians, who use them to study dangerous conditions such as appendicitis in younger and less cooperative children.

Yet the technique exposes patients to tens of times more radiation than conventional X-ray examinations. Brenner says the doses are comparable to those received by people around two kilometres away from the atomic bomb blasts at Hiroshima and Nagasaki in 1945. Extrapolating from the bomb studies, he says that a single CT scan on a newborn girl has a 1 in 800 chance of causing fatal cancer.

Debate about the safety of CT has intensified in the United States this year. Brenner, for example, has highlighted the risks of adult full-body scans (D. Brenner and C. D. Elliston Radiology 232, 735-738; 2004). But he and Elaine Ron, an epidemiologist at the National Cancer Institute in Bethesda, Maryland, who worked with him on the paediatric studies, say the risks to children are only just beginning to be quantified.

Brenner says that the benefits of appropriately using the technique almost always outweigh the risks, but adds that many scans could be avoided.A straw poll taken at a
2001 radiology conference, held in Chicago, Illinois, showed that delegates believed that up to $30 \%$ of paediatric scans were unnecessary (Pediatr. Radiol.32, 242-244;2002).

The US Food and Drug Administration, which regulates medical devices, already advises clinicians to use lower radiation doses in children. But a 2001 survey of practice in one US hospital indicated that radiologists may not be doing this (A. Paterson, D. P. Frush and L. F. Donnelly Am. J. Roentgenol. 176, 297-301; 2001). Kieran McHugh, a paediatric radiologist at Great Ormond Street Hospital for Children in London, says UK clinicians are becoming more aware of the issue. "But I still see images taken at adult settings," he adds. "You could use a quarter of the dose."

A proposed epidemiological study by researchers at the University of Newcastle upon Tyne, UK, may provide better data on the risks. Mark Pearce and Louise Parker hope to study the hospital records of 100,000 children who received scans. But Pearce cautions that several such studies will be needed to properly assess the risk of CT scans.

\section{Digital mastery peers through cracks at early Picasso}

\section{Barbara Simm}

For almost a century, Pablo Picasso's early painting Rue de Montmartre held a surprising secret. But a few years ago, X-ray analysis showed that beneath its restrained portrayal of some hunched-up figures there lurked a very different painting of the decadent side of Parisian nightlife.

Now William Shank, former chief conservator at the San Francisco Museum of Modern Art, has digitally recreated the hidden work in all its colourful glory. Named simply A Hidden Picasso, it is being exhibited for the first time this month at the Guggenheim Museum Bilbao in Spain, to coincide with an international meeting of art conservationists taking place in the city. Shank began with the shadowy, blackand-white image revealed by the $\mathrm{X}$-rays the method used routinely by conservators to see through thin layers of paint. He then identified the painting's original colours, using cameras to peer through the networks of tiny cracks in Rue de Montmartre and computer imaging techniques to build up an image of what lies beneath it.

Experts date the uncovered painting to 1900, which would make it the first work that the artist painted after arriving in Paris from Barcelona at the age of 19 - giving the elusive work special significance for art historians.

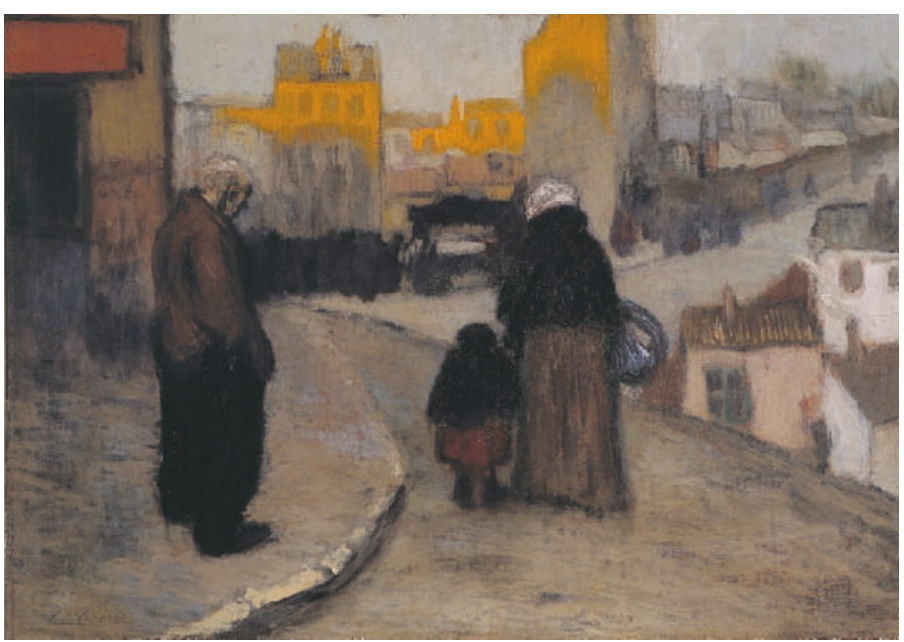

Buried treasure:
beneath Picasso's Rue de Montmartre (left) lies the first picture the artist painted after arriving in Paris. X-rays revealed A Hidden Picasso (below, left), which has now been digitally enhanced to display its original colours.
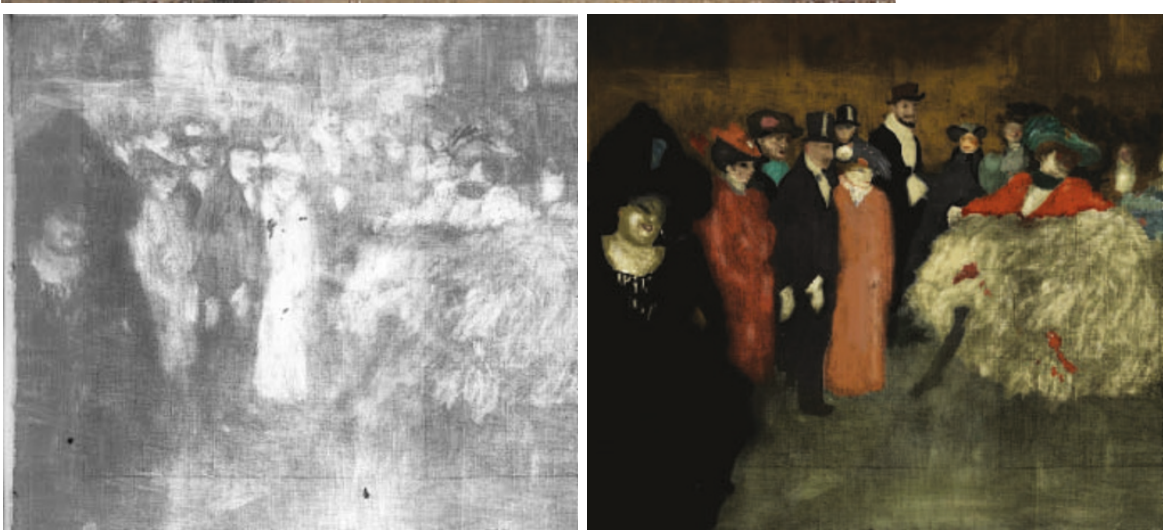